\title{
Peningkatan Kesiapsiagaan Anggota Nasyiatul Aisyiyah (NA) Cabang Ngawen Klaten Terhadap Bencana
}

\author{
Wiliis Diana, Yunita Furi Aristyasari, Restu Faizah dan Edi Hartono \\ Universitas Muhammadiyah Yogyakarta \\ Emai: willis.diana@umy.ac.id, 081392395338
}

\begin{abstract}
Abstrak
Peningkatan keterampilan dan kemampuan individu, keluarga dan masyarakat dalam menghadapi bencana perlu dilakukan terus menerus, mengingat potensi ancaman dan jumlah masyarakat yang terpapar risiko bencana semakin tinggi. Perempuan memiliki peran strategis dalam penanggulangan bencana dan dapat menjadi agen yang efektif untuk mentransfer pengetahuannya kepada generasi berikutnya. Pada Pengabdian masyarakat ini, kelompok Nasyiatul Aisyiyah cabang Ngawen, Klaten, Jawa Tengah menjadi mitra pengabdian, tujuan kegiatan ini adalah untuk meningkatkan kemampuan kesiapsiagaan terhadap bencana. Upaya peningkatan kesiapsiagaan dalam kegiatan ini meliputi kesiapsiagaan jasmani dan rohani. Metode yang dipakai dalam kegiatan ini ada tiga tahapan yang dilakukan pada kegiatan pengabdian masyarakat, tahap pertama dilakukan untuk mengetahui wawasan mitra tentang kesiapsiagaan bencana, dilakukan survey permulaan dengan menggunakan kuesioner, tahapan kedua adalah kegiatan pendidikan kesiapsiagaan bencana dengan bimbingan dari fasilitator, pemberian buku saku siaga bencana, dan diskusi, tahap ketiga adalah evaluasi tentang pemahaman kesiapsiagaan setelah dilakukan pelatihan, evaluasi dilakukan dengan menggunakan kuesioner. Hasil dari survey awal menunjukkan bahwa mitra pengabdian berada pada tingkat kesiapansiagaan sedang. Setelah pendidikan kesiapsiagaan semua parameter indeks kesiapsiagaan mengalami kenaikan, parameter indeks pengetahuan meningkat $5 \%$, rencana kesiapsiagaan keluarga meningkat $15 \%$, pengetahuan tentang sistem peringatan bencana meningkat $6 \%$, dan mobilisasi sumber daya meningkat $10 \%$. Peserta masih memerlukan sosialisasi pengetahuan kebencanaan, simulasi pentingnya evakuasi, pertolongan dan penyelamatan, dan sosialisasi dan kampanye tentang bencana melalui media yang sesuai dengan kondisi masyarakat.
\end{abstract}

Kata Kunci : Kesiapsiagaan, siaga jasmani dan rohani, Nasyiatul Aisyiyah cabang Ngawen

\section{Abstract}

Increasing the skills and abilities of individuals, families and communities in the face of disasters need to be carried out continuously, because of the high potential for threats and the increasing number of people exposed to disaster risk. Women have a strategic role in disaster management and are very effective in transferring their knowledge to the next generation. In this community service activity, the Nasyiatul Aisyiyah branch of Ngawen, Klaten, Central Java, was chosen as a partner. The purpose of this activity is to improve women's preparedness capacity and to reduce people's exposure to disasters. The activities are not only in terms of physical preparedness but also spiritual preparedness. This community service activity consist of three stage, which are, the first stage is preliminary survey to assess the knowledge of participants on disaster preparedness, the second stage is giving disaster preparedness education with facilitators guidance, providing disaster preparedness pocket books, and discussions, and the final stage was an assessment of disaster preparedness after participants are given education/training. The assessment was done using a questionnaire. The result of the preliminary survey shows that the participants are at the level of moderate preparedness. The disaster preparedness education increasing all the disaster preparedness 
parameters index. The knowledge parameter index increased by 5\%, the family preparedness plan parameter index increased by $15 \%$, the parameter index of disaster warning knowledge increased by $6 \%$, the resource mobilization parameter index increased by $10 \%$. The socialization or simulation is needed about the importance of evacuation, relief and rescue, and campaigns about the disaster are also needed through various media that are in accordance with the conditions of the community.

Keywords: Preparedness, physical and spiritual preparedness, Nasyiatul Aisyiyah cabang Ngawen

\section{PENDAHULUAN}

Berdasarkan data dari Badan Nasional Penanggulangan Bencana (BNPB), jumlah kejadian bencana di Indonesia meningkat 20 kali lipat dalam waktu 15 tahun (2002 - 2016). Lebih dari 90\% korban meninggal dunia dan hilang akibat bencana, disebabkan oleh gempa bumi dan tsunami (Amri, 2017). Jenis bencana yang dominan terjadi di wilayah Indonesia adalah gempa bumi, tsunami, letusan gunung api, banjir, tanah longsor, kekeringan, kebakaran lahan dan hutan, cuaca ekstrim, dan gelomang pasang/abrasi.

Dalam peta Indeks Risiko Bencana Indonesia tahun 2013 yang ditunjukkan dalam Gambar 1, terlihat bahwa hampir seluruh wilayah Indonesia memiliki risiko tinggi terpapar berbagai jenis bencana (berwarna merah) (Kurniawan dkk., 2014).

Risiko bencana pada sebagian besar wilayah Indonesia dapat dikurangi dengan cara menurunkan besarnya ancaman (hazard) dan tingkat kerentanan (vulnerability) serta meningkatkan kapasitas masyarakat (capacity), sesuai dengan persamaan 1 (Amri et al., 2016). Namun penurunan hazard tidak mungkin dilakukan pada beberapa jenis bencana seperti gempa bumi, tsunami dan letusan gunung api, sehingga usaha yang bisa dilakukan adalah menurunkan vulnerability dan meningkatkan capacity. Usaha menurunkan vulnerability dapat dilakukan dengan meningkatkan kemampuan masyarakat pada sektor fisik, sosial dan lingkungan, sedangkan usaha meningkatkan capacity dapat berupa kesiapsiagaan masyarakat, peringatan dini (early warning), dan mitigasi.

$$
\text { Risk }=\frac{\text { hazard } \times v u \ln \text { erability }}{\text { capacity }}
$$

Perempuan dikonstruksi sebagai kelompok tersubordinasi oleh laki-laki, keterbatasan akses terhadap informasi tak terkecuali ketika terjadi bencana sama pada tahap mitigasi bencana (Hastuti, 2016). Hal tersebut menjadikan perempuan memiliki tingkat kerentanan tinggi dibandingkan laki-laki. Peran dan tanggung jawab yang lebih besar pada perempuan dalam hal keselamatan terhadap anggota keluarga yang lain membuatnya mengorbankan keselamatan sendiri (Murtakhamah, 2013). Perempuan juga harus memiliki kemampuan dan diberi kebebasan dalam mendapatkan informasi serta pengetahuan khususnya tentang bencana, melihat perempuan merupakan kelompok yang memiliki tingkat kerentanan tinggi selain anak-anak, orang lanjut usia dan difabel (Puspitasari, dkk 2018). UU No 24 tahun 2007 tentang penangulangan bencana yang menetapkan prinsip kesetaraan di hadapan hukum dan dalam pemerintah, yang berarti bahwa isi ketentuan dalam penaggulangan bencana tidak dapat terkait dengan masalah yang membedakan latar belakang, agama, ras, kelompok, gender atau status sosial. Prinsip ini juga berlaku saat memberi ketentuan terkait peringatan dini yang diidentifikasi sebagai salah satu kegiatan pra bencana dalam UU No 24 tahun 2007. Perempuan memiliki kapasitas dalam penanggulangan bencana (Puspitasari, dkk, 2018), sehingga pendidikan dan pelatihan terhadap kesiapsiagaan bencana untuk perempuan sangat diperlukan.

Upaya kesiapsiagaan yang dilakukan pada saat bencana mulai teridentifikasi akan terjadi antara lain: (i) pengaktifan pos-pos siaga bencana dengan segenap unsur pendukungnya, (ii) pelatihan 
siaga/simulasi/gladi/teknis bagi setiap sektor penanggulangan bencana (SAR, sosial, kesehatan, prasarana dan pekerjaan umum), (iii) inventarisasi sumber daya pendukung kedaruratan, (iv) penyiapan dukungan dan mobilisasi sumberdaya/logistik, (v) penyiapan sistem informasi dan komunikasi yang cepat dan terpadu guna mendukung tugas kebencanaan, (vi) penyiapan dan pemasangan instrumen sistem peringatan dini (early warning), (vii) penyusunan rencana kontinjensi (contingency plan), dan (viii) mobilisasi sumber daya (personil dan prasarana/sarana peralatan). Upaya peningkatan kesiapsiagaan masyarakat juga dapat dilakukan manakala belum terdeteksi adanya bencana akan terjadi, yaitu dengan beberapa kegiatan seperti (i) penyuluhan (pendidikan kebencanaan), (ii) pembuatan peta rawan bencana, (iii) pelatihan, (iv) pengembangan sumber daya manusia (SDM), (v) analisis risiko dan bahaya, (vi) penelitian dan pengembangan (litbang), dan lainlain (BNPB, 2008).

Kajian tingkat kesiapsiagaan masyarakat menggunakan kerangka yang dikembangkan LIPI bekerja sama dengan UNESCO/ISDR pada tahun 2006. Ada lima parameter yang digunakan dalam mengkaji tingkat kesiapsiagaan masyarakat dalam mengantisipasi bencana yaitu 1) pengetahuan dan sikap tentang risiko bencana; 2) Kebijakan dan panduan; 3) rencana tanggap darurat; 4)sistem peringatan bencana; dan 5) mobilisasi sumber daya. (Hidayati, dkk, 2011). Tingkat kesiapsiagaan rumah tangga /keluarga mengacu pada Tabel 1.

Kegiatan pengabdian bertujuan salah satu upaya untuk meningkatkan kesiapsiagaan masyarakat khususnya kaum perempuan agar memiliki capacity yang memadai, sehingga meminimalkan keterpaparan akibat bencana. Kesiapsiagaan (preparedness) merupakan serangkaian kegiatan yang dilakukan untuk mengantisipasi bencana melalui pengorganisasian serta melalui langkah yang tepat guna dan berdaya guna (Faizah et al., 2019). Dalam Perka BNPB No. 4 tahun 2008 (BNPB, 2008) dijelaskan bahwa kesiapsiagaan dilaksanakan untuk mengantisipasi kemungkinan terjadinya bencana guna menghindari jatuhnya korban jiwa, kerugian harta benda dan berubahnya tata kehidupan masyarakat. Dalam kegiatan penanggulangan bencana, masyarakat berperan sebagai subjek sekaligus objek, artinya masyarakat menjadi pelaku awal penanggulangan bencana sekaligus korban bencana yang harus mampu dalam batasan tertentu menangani bencana, sehingga diharapkan bencana tidak berkembang ke skala yang lebih besar.

\section{BAHAN DAN METODE}

Mitra Pengabdian kepada Masyarakat (PKM) ini adalah anggota Nasyiatul Aisyiyah (NA) cabang Ngawen, kabupaten Klaten, Propinsi Jawa Tengah. NA adalah organisasi remaja putri yang merupakan salah satu organisasi otonom Muhammadiyah. Sebagian anggota merupakan remaja putri yang akan menghadapi masa pernikahan, dan beberapa lainnya sudah menikah dengan usia pernikahan yang masih tergolong muda. Usia ini tergolong pada usia produktif, sehingga sangat efektif diberikan pendidikan kebencanaan, untuk menekan tingkat risiko bencana. Selain itu, wanita siaga merupakan investasi yang cukup efektif, karena wanita memiliki peran yang sangat tinggi dalam keluarga.

Hingga kegiatan pengabdian kepada masyarakat ini dilakukan, belum pernah dilakukan usaha peningkatan kesiapsiagaan mitra, sehingga kegiatan harus diawali dari penyadaran akan bahaya yang ada di sekitar mitra, dan membekali mitra dengan pengetahuan praktis untuk penyelamatan diri dan keluarga apabila terjadi bencana. Dengan adanya pengetahuan tersebut, diharapkan dapat terbentuk wanita siaga pada anggota NA cabang Ngawen, Klaten, Jawa Tengah. 
Kegiatan pengabdian kepada masyarakat ini dilakukan dengan beberapa metode sebagai berikut:

1. Survei kesiapsiagaan individu.

Untuk mengetahui kesiapsiagaan yang dimiliki oleh peserta, dilakukan survei menggunakan kuosioner yang diisi sebelum kegiatan (pretest) dan sesudah kegiatan (posttest). Pokok-pokok isi kuosiner meliputi 5 aspek yaitu, pengenalan tempat, pengetahuan tentang bencana, rencana kesiapsiagaan keluarga dari bencana, peringatan bencana (early warning), mobilisasi sumberdaya.

2. Pendidikan kebencanaan untuk meningkatkan kesiapsiagaan

Kesiapsiagaan yang dimaksud disini meliputi kesiapsiagaan pada aspek jasmani (fisik) dan aspek ruhani (mental). Pendidikan diberikan dengan cara penjelasan dari narasumber menggunakan bantuan slide berisi gambar dan video, serta tanya jawab dan diskusi. Pokok-pokok diskusi dan penjelasan narasumber mencakup beberapa hal, seperti:

a. Potensi bencana: peserta diajak berdiskusi dengan dipandu oleh seorang fasilitator untuk mengenali berbagai jenis bencana yang pernah terjadi di lokasi beserta tingkat ancamannya. Dalam diskusi ini fasilitator berusaha memberikan pemahaman kepada peserta tentang beberapa jenis bencana dan tingkat bahayanya menggunakan bantuan slide yang berisi teks, gambar dan video. Selanjutnya peserta diminta menyampaikan pengalaman dan cerita yang pernah dia terima tentang peristiwa bencana di lokasi tersebut. Pada akhir diskusi, fasilitator membantu menyimpulkan jenis bencana dinilai dominan.

b. Kesiapsiagaan jasmani: risiko bencana, komponen-komponen bencana, pengurangan risiko bencana, cara penyelamatan diri, tas siaga bencana, kearifan local (local wisdom), mitigasi bencana, dan pengenalan beberapa jenis bencana alam.

c. Kesiapsiagaan Rohani: hakikat bencana (musibah), hikmah musibah dan bekal kesiapsiagaan Rohani ketika menghadapi musibah.

3. Pembagian buku saku.

Buku saku berisi tentang kiat-kiat praktis yang perlu diketahui agar memiliki kesiapsiagaan. Kiat-kiat ini meliputi kiat sebelum, ketika terjadi, dan setelah terjadi bencana, baik dari aspek jasmani maupun rohani.

\section{HASIL}

Survei diikuti oleh 35 peserta, menggunakan kuosioner pretest dan posttest. Gambar 2 menunjukkan suasana ketika peserta sedang mengisi kuosioner. Kuosioner yang telah terisi kemudian dianalisis untuk mengetahui kesiapsiagaan yang dimiliki peserta sebelum mengikuti kegiatan pengabdian ini dengan kesiapsiagaan setelah mengikuti kegiatan pengabdian. Dari hasil analisis, diperoleh data bahwa peserta mengalami peningkatan kesiapsiagaan dari sebelum hingga sesudah mengikuti kegiatan pengabdian. Sebanyak $86 \%$ peserta merasa tidak tahu tentang beberapa hal, kemudian menjadi tahu setelah mengikuti kegiatan pengabdian, seperti ditunjukkan pada Gambar 3. Peningkatan dari 30 orang (86\%) peserta meliputi peningkatan pada pengertian beberapa hal berikut ini: gempa tidak dapat diprediksi, ciri bangunan tahan gempa dan tsunami, penyelamatan diri dan keluarga dari bahaya gempa dan tsunami, Early Warning System (EWS), tas siaga bencana, sikap ketika gempa, siaga gempa (tempat berkumpul, jalur evakuasi, rute pengungsian, persediaan makanan), sumber informasi EWS, tanda tsunami, penyebab gempa, pengertian bencana, investasi untuk kesiapsiagaan bencana.

Hasil penilaian dari kuisioner sebelum dan setelah pendidikan kesiapsiagaan bencana diperoleh indeks parameter untuk empat kategori yaitu pengetahuan tentang bencana, rencana kesiapsiagaan keluarga dari bencana, pengetahuan peringatan dini bencana, dan mobilisasi sumber 
daya, indeks masing masing parameter ditunjukkan pada Gambar 4. Hasil survey awal menunjukkan bahwa peserta pendidikan kesiapsiagaan bencana berada pada tingkat kesiapsiagaan sedang, setelah pendidikan kesiapsiagaan bencana, indeks parameter pengetahuan meningkat sebesar 5\%, indeks parameter rencana kesiapsiagaan keluarga meningkat sebesar $15 \%$, indeks pengetahuan tentang peringatan dini meningkat sebesar $6 \%$, dan indeks parameter mobilisasi sumber daya meningkat sebesar $10 \%$.

\section{PEMBAHASAN}

Pada awal diskusi, peserta diajak untuk mengidentifikasi potensi-potensi bencana yang pernah terjadi dan kemungkinan terulang kembali pada daerah mereka, diperoleh informasi daftar bencana alam yang sudah pernah terjadi di lokasi, yaitu angin puting beliung, gempabumi dan banjir. Respon baik secara fisik maupun psikis peserta terhadap kejadian-kejadian bencana yang telah terjadi, menganalisis apakah respon peserta tersebut sudah tepat atau kurang tepat, dan memberikan pemahaman bagaimana seharusnya peserta menyikapi kejadian bencana tersebut. Diskusi berlangsung menarik dan interaktif, peserta sangat antusias dan menginginkan pelatihan kembali, menyarankan agar segiatan sejenis dilakukan secara menerus dan ditingkatkan menjadi kegiatan pelatihan dan simulasi. Dokumentasi kegiatan ditunjukkan dalam Gambar 5.

Dari hasil survei melalui kuesioner diperoleh informasi bahwa kegiatan peningkatan kesiapsiagaan terhadap bencana sangat perlu dilakukan. Selain itu, peserta juga mengharapkan adanya kelanjutan kegiatan serupa. Adapun usaha peningkatan kesiapsiagaan yang menjadi rekomendasi peserta adalah sebagai berikut: menambah pengetahuan tentang bencana yang berpotensi terjadi, membuat rencana evakuasi, simulasi evakuasi keluarga, pengetahuan mengenai rumah tahan gempa, persiapan evakuasi (makanan dan pakaian), penentuan titik kumpul, persiapkan hal-hal penting seperti dokumen penting, kotak P3K dan kebutuhan darurat keluarga, dan menyiapkan alat komunikasi alternatif. Secara umum peserta masih memerlukan sosialisasi tentang pengetahuan kebencanaan, simulasi pentingnya evakuasi, pertolongan dan penyelamatan, dan sosialisasi dan kampanye tentang bencana melalui media yang sesuai dengan kondisi masyarakat.

Pemberian buku saku kesiapsiagaan bencana kepada peserta dilakukan agar peserta dapat lebih memahami, manjadi pengingat, dan pedoman untuk kesiapsiagaan baik secara fisik maupun mental (psikis) sebelum dan setelah bencana terjadi. Buku saku seperti disajikan dalam Gambar 6 .

\section{KESIMPULAN DAN SARAN}

Kegiatan pengabdian kepada masyarakat untuk meningkatkan kesiapsiagaan anggota NA cabang Ngawen, Klaten, Jawa Tengan telah dilaksanakan dan mendapat sambutan yang sangat baik dari peserta. Setelah mengikuti kegiatan terdapat $86 \%$ dari anggota merasakan manfaatnya dalam peningkatan kesiapsiagaan menghadapi bencana. Hasil survey awal menunjukkan bahwa peserta pendidikan kesiapsiagaan bencana berada pada tingkat kesiapsiagaan sedang, setelah pendidikan kesiapsiagaan bencana, indeks parameter pengetahuan meningkat sebesar $5 \%$, indeks parameter rencana kesiapsiagaan keluarga meningkat sebesar $15 \%$, indeks pengetahuan tentang peringatan dini meningkat sebesar $6 \%$, dan indeks parameter mobilisasi sumber daya meningkat sebesar $10 \%$. Peserta juga mengharapkan agar kegiatan serupa dilanjutkan dengan kegiatan seperti simulasi dan pelatihan kesiapsiagaan. 


\section{UCAPAN TERIMA KASIH}

Penulis mengucapkan terima kasih setinggi-tingginya kepada Universitas Muhammadiyah Yogyakarta (UMY) yang telah memberikan dukungan untuk terselenggaranya kegiatan ini melalui Lembaga Penelitian, Publikasi dan Pengabdian kepada masyarakat (LP3M). Selain itu penghargaan diberikan kepada pimpinan cabang Nasyiatul Aisyiyah Ngawen, Klaten, Jawa Tengah yang telah bersedia menjadi mitra kegiatan ini.

\section{DAFTAR PUSTAKA}

Amri, A., 2017. Pendidikan Tangguh Bencana. Sekretariat Nasional SPAB, Jakarta.

Amri, M.R., Yulianti, G., Yunus, R., Wiguna, S., 2016. RBI, Risiko Bencana Indonesia. BNPB Direktorat Pengurangan Risiko Bencana, Jakarta.

BNPB, 2008. Peraturan Kepala Badan Nasional Penanggulangan Bencana (BNPB) No. 4 tahun 2008 tentang pedoman penyusunan rencana penanggulangan bencana.

Deviani, E., 2013. “Analisis Kesiapsiagaan Dan Kerentanan Perempuan di Wilayah Pesisir Dalam menghadapi Bencana Gempa dan Tsunami di Banda Aceh", Idea Nursing Journal, 4(3).

Faizah, R., Diana, W., Hartono, E., Aristyasari, Y.F., 2019. Buku Saku Siaga Jasmani dan Rohani Menghadapi Bencana. UMY, Yogyakarta.

Hidayati, D., Hidayatun, Hartana, P., Triyono, Kusumawati,T., 2011, Panduan Mengukur Tingkat Kesiapsiagaan Masyarakat dan Komunitas Sekolah, LIPI

Hastuti. 2016. "Peran Perempuan Dalam Menghadapi Bencana Di Indonesia”. Geomedia Volume 14 Nomor 2.

Kurniawan, L., Triutomo, S., Yunus, R., Amri, M.R., Hartyanto, A.A., 2014. IRBI, Indeks Risiko Bencana Indonesia 2013. Direktorat Pengurangan Risiko Bencana, Deputi Bidang Pengurangan dan Kesiapsiagaan BNPB.

Murtakhamah, T., 2013. “Pentingnya Pengarusutamaan Gender Dalam Program Pengurangan Resiko Bencana”. Welfare Jurnal IImu Kesejahteraan Sosial, 2(1), pp.37-54.

Puspitasari, A.E., Dewi, T.P., Ruslanjari, D., 2018, "Partisipasi Perempuan Dalam Penanggulangan Bencana di Desa Pagerharjo, Kecamatan Samigaluh", Prosiding PIT ke-5 Riset Kebencanaan IABI, Universitas Andalas, Padang 2-4 Mei, 363-376

Undang-undang Republik Indonesia nomor 24 tahun 2007 tentang Penanggulangan Bencana.

Widjanarko, M. and Minnafiah, U., 2018. "Pengaruh pendidikan bencana pada perilaku kesiapsiagaan siswa". Jurnal Ecopsy, 5(1), pp.1-7. 


\section{LAMPIRAN}

Tabel 1. Tingkat Kesiapsiagaan rumah tangga/keluarga (Hidayati, dkk 2011)

\begin{tabular}{|l|l|l|}
\hline No. & Nilai indeks & Kategori \\
\hline 1. & $80-100$ & Kesiapsiagaan Tinggi \\
\hline 2. & $60-79$ & Kesiapsiagaan Sedang \\
\hline 3. & $<60$ & Kesiapsiagaan Rendah \\
\hline
\end{tabular}

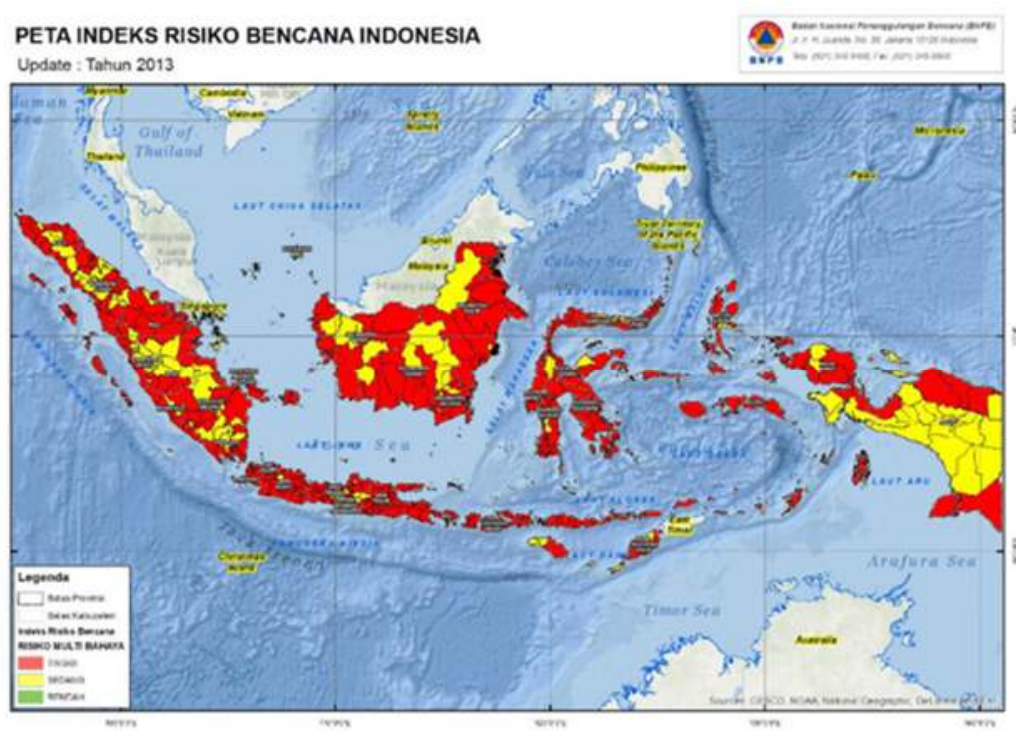

Gambar 1. Peta Indeks Risiko Bencana Indonesia tahun 2013 (Kurniawan et al., 2014)

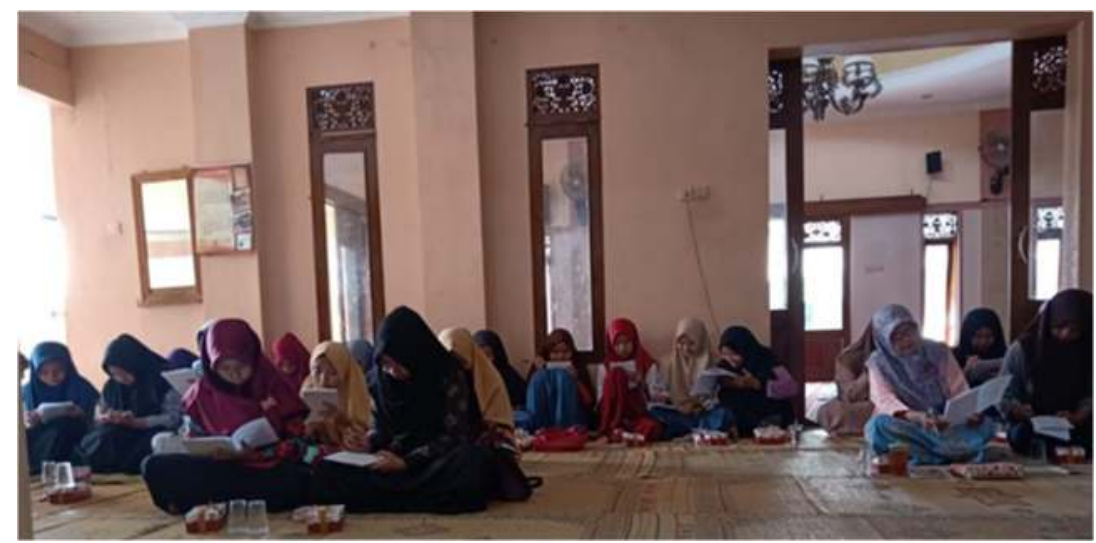

Gambar 2. Suasana pengisian kuosioner 


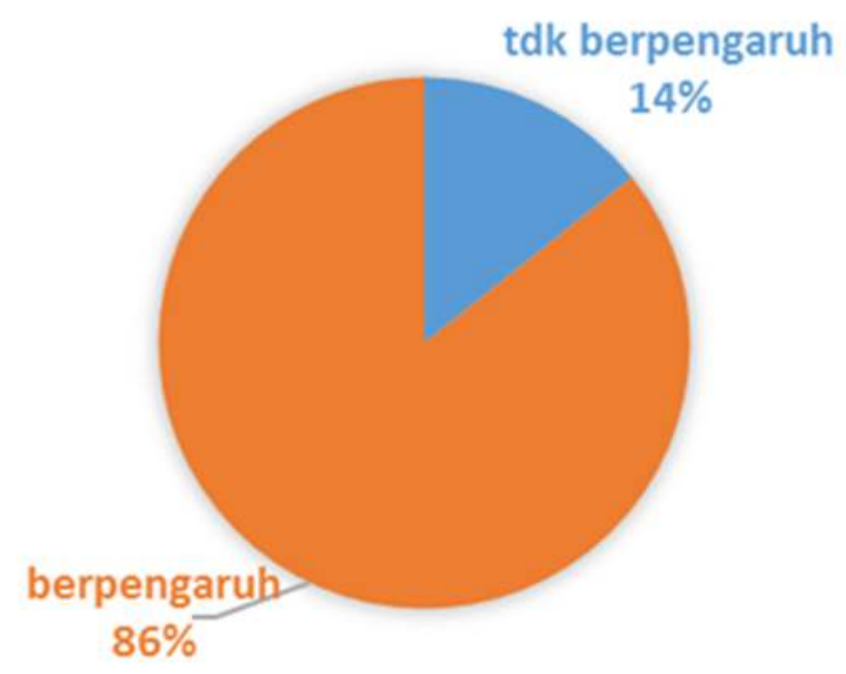

Gambar 3. Prosentase peserta yang mengalami peningkatan kesiapsiagaan

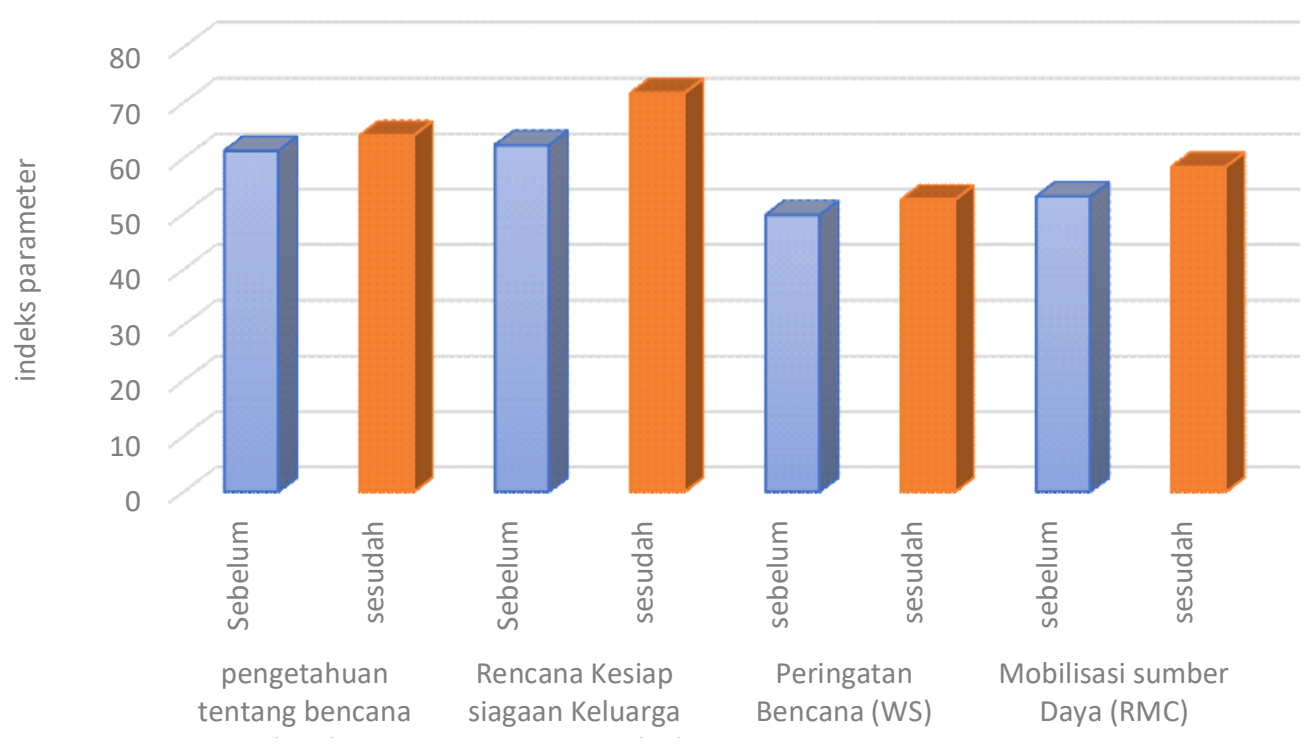

Gambar 4. Hasil penilaian indeks parameter kesiapsiagaan sebelum dan sesudah pendidikan kebencanaan 

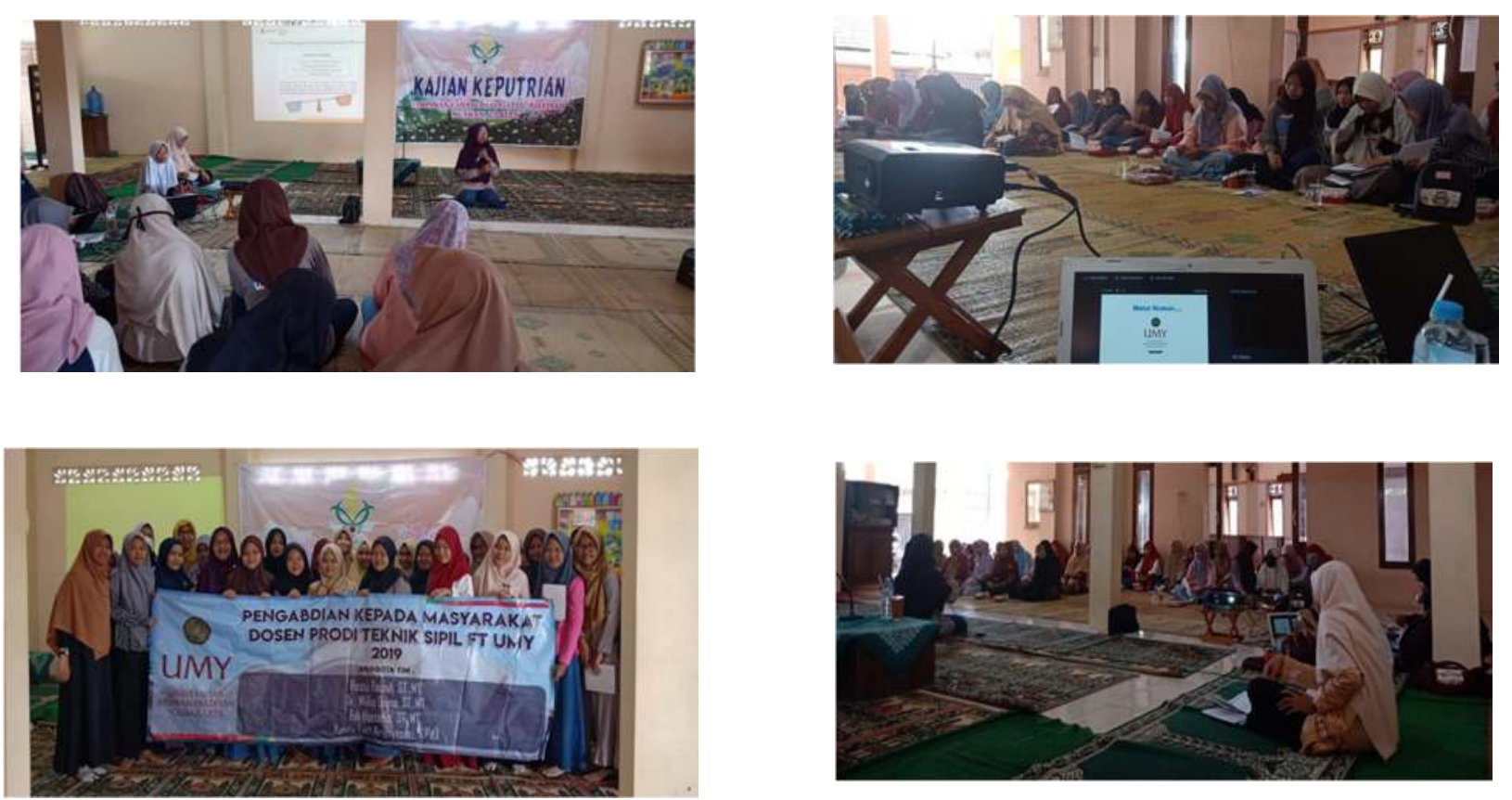

Gambar 5. Dokumentasi kegiatan pendidikan kesiapsiagaan.
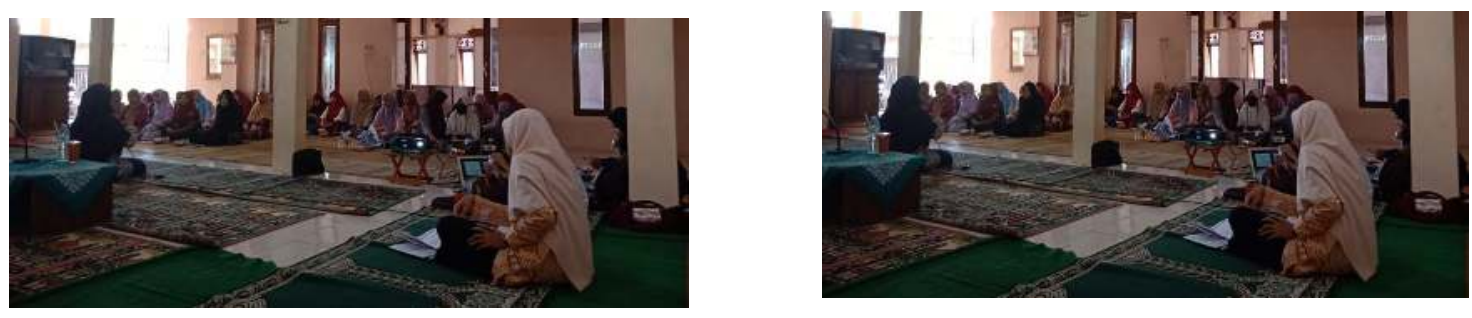

Gambar 6. Dokumentasi kegiatan pendidikan kesiapsiagaan 